\title{
¿CONTINUIDAD ELECTORAL EN BRASIL?
}

Brasil ha celebrado sus séptimas elecciones presidenciales desde la transición democrática revalidando la pauta reeleccionista que inaugurara Fernando $\mathrm{H}$. Cardoso y prosiguiera Lula da Silva. En esta ocasión la presidenta Dilma Rousseff ha sido reelegida, pudiendo cumplir un ciclo de ocho años en el gobierno como sus predecesores. Por otra parte, y a diferencia del periodo de Cardoso en el que su partido, el PSDB, fue la formación sobre la que se articuló el gobierno de coalición, en esta ocasión el PT será el eje sobre el que gire la política brasileña durante dieciséis años, siendo uno de los periodos más largos con un mismo partido en el gobierno de los últimos treinta años en América Latina.

Las elecciones brasileñas del 5 de octubre de 2014, que contaron con la circunstancia luctuosa de la desaparición durante la campaña de uno de los candidatos favoritos (Eduardo Campos, del PSB), registraron la presencia en la primera vuelta de once candidatos que, no obstante, vieron restringidas sus posibilidades a únicamente tres: la propia Rousseff, Aécio Neves del PSDB y Marina Silva del PSB, quien ya fue candidata en las elecciones inmediatamente anteriores y que ahora reemplazaba al fallecido Campos. Estos tres candidatos se repartieron más del $96 \%$ de los votos recogiendo, por consiguiente, de forma abrumadora las preferencias del electorado que, por el contrario, volvía a mostrar un comportamiento enormemente fraccionado en lo atinente a las elecciones legislativas, en las que veintinueve partidos alcanzaron representación parlamentaria. Tres semanas más tarde, en la segunda vuelta que enfrentó a Rousseff con Neves, se produjo el triunfo de la primera por un margen de tres puntos porcentuales, siendo el margen más estrecho con el que un presidente brasileño gana unas elecciones desde 1989.

El panorama político brasileño enfrenta un escenario en el que se mantendrá el esquema de presidencialismo de coalición según el cual el gobierno se ve conformado por un alto número de partidos que brindan cierta estabilidad a la acción del mismo. La heterogeneidad de los miembros de la coalición ha puesto siempre en duda el carácter de bloque ideológico gubernamental, siendo también ésta una de las características tradicionales del sistema político brasileño. Además debe tenerse en cuenta el necesario equilibrio que debe establecerse asimismo con los gobernadores de los estados donde se evidencia también la gran pluralidad del mapa político brasileño.

El presente número aborda tres análisis de sendos aspectos de la pasada coyuntura electoral que tienen particular relevancia. Wladimir Gramacho presta especial atención al fenómeno de las encuestas preelectorales, un apartado especialmente sensible por la sobrevaloración que confirieron a la candidata del PSB. El texto de Rodrigo Rodrigues-Silveira hace notable hincapié en la relación existente entre demografía y voto en barrios de tres ciudades capitales. Finalmente, Michelle Fernández, Ernani Carvalho y Enivaldo Rocha analizan el nivel de la competencia partidista en los diferentes estados brasileños. Se trata, por consiguiente, de tres estudios llevados a cabo por profesionales brasileños vinculados de una u otra manera a la Universidad de Salamanca, que abordan facetas del proceso electoral pasado desde perspectivas diferentes y poniendo el acento en cuestiones que muchas veces no son tenidas en cuenta.

\section{Prof. Dr. Manuel Alcántara Sáez}

Catedrático de Ciencia Política

Facultad de Ciencias Sociales

Universidad de Salamanca

malcanta@usal.es 